\title{
Answer to the letter to the editor of Carl Hans Fürstenberg et al. (2010) concerning manuscript "transforaminal endoscopic surgery for lumbar stenosis: a systematic review" by Jorm Nellensteijn, Raymond Ostelo, Ronald Bartels, Wilco Peul, Barend Van Royen, Maurits Van Tulder. Eur Spine J 19:879-886
}

\author{
Raymond Ostelo
}

Published online: 27 November 2010

(C) The Author(s) 2010. This article is published with open access at Springerlink.com

In the letter to the editor it is suggested that we might have missed relevant evidence. Not including 'discectomy' in the search strategy is pointed out as the main reason. But apparently there is confusion regarding the fact that we published two systematic reviews, both on transforaminal endoscopic surgery. One focuses on symptomatic lumbar disc herniations [1] and the second one on lumbar stenosis [2]. We combined the search strategy for these two reviews for efficiency reasons. The keywords were used as MESH headings and free text words; discectomy was included in the search strategy [1]. The full search strategy is available upon request.

In the present review we focus on stenosis. The SCIATICA-Med trial [3, 4] included patients with lumbar disc herniation and was therefore not eligible for this review. Moreover, it clearly uses a different technique than the transforaminal endoscopic surgery. Therefore, this study was also excluded from our systematic review on symptomatic lumbar disc herniations [1]. The German health technology assessment report [5] focuses on the treatment of disc prolapse and not stenosis. The study by Hermantin et al. [6] met the inclusion criteria for review on symptomatic lumbar disc herniations [1] and was included (see Ref. 11 of that review). The report by the Dutch Health Care Insurance also focuses on lumbar disc herniation and was based on our review [1]. The three key publications [7-9] that we reportedly 'omitted' were included in our review on symptomatic lumbar disc herniations [1] as they included patients with lumbar disc herniation. The study by

\section{R. Ostelo $(\bowtie)$}

EMGO Institute, VU University Medical Centre and Institute for Health Sciences, VU University, van der Boechorststraat 7, 1081 BT Amsterdam, The Netherlands

e-mail: r.ostelo@vumc.nl
Molyneux was not found as our search strategy was up to November 2009. Conference proceedings did not meet our definition of 'published papers' and therefore Lewandrowski [10] and Iprenburg [11] were not included. The reference by Morgenstern [12] could not be retrieved, as the European Musculoskeletal Review seems not to be indexed in the databases we searched. The study by Hoogland [13] includes patients with recurrent lumbar disc herniation, not stenosis.

In assessing the risk of bias, we followed the guidelines of the Cochrane Back Review Group and, therefore, we think that the doubt the authors convey regarding 'the publication quality assessment criteria' is without any foundation.

In conclusion, no randomized controlled trial, but only seven observational studies were identified and no relevant papers are missed. All these studies had a high risk of bias. Consequently, the conclusion that there is no valid evidence on the effectiveness of transforaminal endoscopic surgery for lumbar stenosis is supported by the data.

Conflict of interest None.

Open Access This article is distributed under the terms of the Creative Commons Attribution Noncommercial License which permits any noncommercial use, distribution, and reproduction in any medium, provided the original author(s) and source are credited.

\section{References}

1. Nellensteijn J, Ostelo R, Bartels R et al (2010) Transforaminal endoscopic surgery for symptomatic lumbar disc herniations: a systematic review. Eur Spine J 19(2):181-204

2. Nellensteijn J, Ostelo R, Bartels R et al (2010) Transforaminal endoscopic surgery for lumbar stenosis: a systematic review. Eur Spine J 19:879-886 
3. http://www.controlled-trials.com/ISRCTN51857546. Accessed on July 262010

4. Arts MP, Peul WC, Brand R et al (2006) Cost-effectiveness of microendoscopic discectomy versus conventional open discectomy in the treatment of lumbar disc herniation: a prospective randomised controlled trial [ISRCTN51857546]. BMC Musculoskelet Disord 13:7-42

5. Lühmann D, Burkhardt-Hammer T, Borowski C et al (2005) Minimal invasive procedures for the treatment of disc prolapse. HTA-Bericht 17. Deutsche Agentur für Health Technology Assesment

6. Hermantin FU, Peters T, Quartararo L et al (1999) A prospective, randomized study comparing the results of open discectomy with those of video-assisted arthroscopic microdiscectomy. J Bone Joint Surg Am 81:958-965

7. Iprenburg M (2007) Transforaminal endoscopic surgery-technique and provisional results in primary disc herniation. Eur Musculoskelet Rev 73-76

8. Hoogland T (2003) Transforaminal endoscopic discectomy with foraminoplasty for lumbar disc herniation. Surg Tech Orthop Traumatol 40:55-120
9. Ruetten S, Komp M, Merk H et al (2008) Full-endoscopic interlaminar and transforaminal lumbar discectomy versus conventional microsurgical technique: a prospective, randomized, controlled study. Spine 33:931-939

10. Lewandrowski K, Morgenstern R (2008) Endoscopic lumbar foraminal decompression for stenosis. Society for Minimally Invasive Spine Surgery. 2008 Annual Meeting. No 79

11. Iprenburg M, Bloemsaat J, Godschalx A (2008) Transforaminal endoscopic discectomy: Clinical results compared with microscopic discectomies Swedish National Spine Register. Society for Minimally Invasive Spine Surgery. 2008 Annual Meeting. No 48

12. Morgenstern R (2009) Transforaminal Endoscopic Stenosis Surgery: a Comparative Study of Laser and Reamed Foraminoplasty. Eur Musculoskelet Rev 4(1)

13. Hoogland T, van den Brekel-Dijkstra K, Schubert M et al (2008) Endoscopic Transforaminal Discectomy for Recurrent Lumbar Disc Herniation. Spine 33:973-978 